University of Wollongong

Research Online

Faculty of Engineering and Information

Faculty of Engineering and Information

Sciences - Papers: Part A

Sciences

$1-1-2012$

Drying shrinkage of concrete made from recycled concrete aggregate

\author{
B A. Whiting \\ University Of Wollongong \\ T J. McCarthy \\ University of Wollongong, timmc@uow.edu.au \\ E Lume \\ University of Wollongong, elume@uow.edu.au
}

Follow this and additional works at: https://ro.uow.edu.au/eispapers

Part of the Engineering Commons, and the Science and Technology Studies Commons

Research Online is the open access institutional repository for the University of Wollongong. For further information contact the UOW Library: research-pubs@uow.edu.au 


\title{
Drying shrinkage of concrete made from recycled concrete aggregate
}

\begin{abstract}
Recycled concrete aggregates (RCA) are used in new concrete mixes, termed recycled aggregate concrete (RAC). Among losses in most fresh and hardened properties, literature reports that RAC suffers increased levels of drying shrinkage compared to equivalent mixes incorporating conventional aggregates. This paper describes the procedure and results of a range of experiments conducted on a commercial RCA and its use in new concrete mixes. In particular, this work quantifies the effect $100 \%$ RCA has on the drying shrinkage of the resulting concrete. A commercially available RCA was characterised by analysing the particle shape and texture, percentage of solid contaminants, particle size distribution, water absorption and particle densities. The types of rocks present were analysed through the preparation of thin sections. Three concrete mixes were prepared and tested for workability, 7 and 28 day compressive strengths and 112 days of drying shrinkage. The mixes included a $40 \mathrm{MPa}$ control mix incorporating natural crushed aggregates and two equivalent RAC mixes, one with $30 \%$ fly ash as a partial cement replacement and one without. The results indicated that the commercial RCA has been produced quite efficiently with negligible solid contaminants. However, due to adhered mortar found on the aggregate particles, the RCA was found to have rougher particle textures, increased water absorptions and lower densities than conventional crushed aggregates. Due to these properties and the subsequent increased water demand the RAC mixes suffered lower compressive strengths and higher drying shrinkages than the control mix. The RAC mix incorporating no fly ash was found to have a $25 \%$ average increase in the 112 day drying shrinkage from the control mix while the fly ash mix only had a $7 \%$ increase.
\end{abstract}

\section{Keywords}

drying, shrinkage, aggregate, concrete, recycled, made

Disciplines

Engineering | Science and Technology Studies

\section{Publication Details}

Whiting, B. A., McCarthy, T. J. \& Lume, E. (2012). Drying shrinkage of concrete made from recycled concrete aggregate. 22nd Australasian Conference on the Mechanics of Structures and Materials (pp. 1-6). 


\title{
Drying shrinkage of concrete made from recycled concrete aggregate
}

\author{
B.A. Whiting, T.J. McCarthy \& E. Lume \\ School of Civil, Mining and Environmental Engineering, Faculty of Engineering, University of Wollongong, \\ Wollongong, NSW, Australia
}

\begin{abstract}
Recycled concrete aggregates (RCA) are used in new concrete mixes, termed recycled aggregate concrete (RAC). Among losses in most fresh and hardened properties, literature reports that RAC suffers increased levels of drying shrinkage compared to equivalent mixes incorporating conventional aggregates. This paper describes the procedure and results of a range of experiments conducted on a commercial RCA and its use in new concrete mixes. In particular, this work quantifies the effect $100 \%$ RCA has on the drying shrinkage of the resulting concrete. A commercially available RCA was characterised by analysing the particle shape and texture, percentage of solid contaminants, particle size distribution, water absorption and particle densities. The types of rocks present were analysed through the preparation of thin sections. Three concrete mixes were prepared and tested for workability, 7 and 28 day compressive strengths and 112 days of drying shrinkage. The mixes included a $40 \mathrm{MPa}$ control mix incorporating natural crushed aggregates and two equivalent RAC mixes, one with $30 \%$ fly ash as a partial cement replacement and one without. The results indicated that the commercial RCA has been produced quite efficiently with negligible solid contaminants. However, due to adhered mortar found on the aggregate particles, the RCA was found to have rougher particle textures, increased water absorptions and lower densities than conventional crushed aggregates. Due to these properties and the subsequent increased water demand the RAC mixes suffered lower compressive strengths and higher drying shrinkages than the control mix. The RAC mix incorporating no fly ash was found to have a $25 \%$ average increase in the 112 day drying shrinkage from the control mix while the fly ash mix only had a $7 \%$ increase.
\end{abstract}

\section{INTRODUCTION}

One area that has been the subject of much research and investigation in recent times is how to reduce the quantity of demolition and construction waste sent to landfill. According to the Australian Bureau of Statistics (2007), the construction and demolition industry contributed to $42 \%$ of the solid waste produced in 2002-2003. Of this, only 44\% was recycled in some form, with the remaining waste being sent to landfill. While landfill can result in some positive outcomes such as reclaiming land from disused quarries, a report prepared for the Department of the Environment, Water, Heritage and Arts by Hyder Consulting Pty Ltd (Pickin 2009) has found many regions throughout Australia are reaching their landfill capacities. The paper argues, 'the available supply of landfill is a scarce resource that should be used conservatively' (Pickin 2009, p2). Continued studies investigating ways to encourage the recycling of construction and demolition waste materials are valuable to reduce the percentage of waste going to landfill and to create a more sustainable future.
The key issues facing any recycled product are that they need to be safe, perform well and be economical. There are many concerns regarding the performance of concrete made from RCA. Use of RCA has been reported to provide a loss in most fresh and hardened properties of concrete (Poon et al. 2007). Essentially, this is due to the presence of less dense and more porous mortar adhered to the RCA rock particles (Montgomery \& Sturgis 1996). CSIRO's guide to the use of RCA in concrete proposes that RCA can be used in low grade concrete applications such as pavements. It further recommends only replacing 30\% of the virgin coarse aggregate with high quality RCA (CSIRO 2002). One of the main reasons for this low percentage of substitution is to control the high drying shrinkage of concrete made from RCA (CSIRO 2002, Poon et al. 2007, SagoeCrentsil et al. 2001).

This paper outlines an experimental programme that investigated the drying shrinkage of RAC incorporating effectively $100 \%$ RCA as a replacement for natural coarse aggregate. If more RCA could be used 
in a mix, the greater the theoretical demand for the product, and thus less waste could be sent to landfill.

It was reported by Poon et al. (2007) that fly ash as a $25-35 \%$ partial cement replacement can reduce the drying shrinkage of RAC. This has been opposed by results from other studies such as Corinaldesi \& Moriconi (2009). This paper details a series of experiments aimed to test this finding by Poon et al. (2007).

Identifying ways to improve the performance of RCA has the potential to increase its use and therefore eventually reduce the amount of waste sent to landfill, allowing for more sustainable practice. One way to achieve this is to examine in depth the properties of RCA and the concrete that it is used in.

\section{EXPERIMENT PROGRAM}

\subsection{Materials}

\subsubsection{Aggregates}

A commercial $20 \mathrm{~mm}$ nominal size RCA was sourced from a Western Sydney recycling plant. This aggregate was characterised by a range of aggregate property tests and used in two concrete mixes tested in this study. Local $10 \mathrm{~mm}$ and $20 \mathrm{~mm}$ nominal sized crushed basalt aggregate was used as a control aggregate for both aggregate property testing and concrete testing. A fine Kurnell sand and coarse Emu Plains sand were used in the concrete mixes.

The RCA and $20 \mathrm{~mm}$ control aggregate were tested and analysed for particle shape and texture, percentage of solid contaminants, particle size distribution, water absorption and particle density. A range of rock particles from the RCA were prepared into thin sections to gain a qualitative understanding of the types of rocks present in the RCA product used in the aggregate and concrete testing. A total of twenty-one aggregate particles were prepared into thin sections and analysed.

\subsubsection{Binders}

A General Purpose cement was used in the concrete mixes. One mix incorporated a low-calcium fly ash as a $30 \%$ partial cement replacement. The properties and composition of this fly ash are shown in Table 1.

Table 1. Fly ash properties/composition

\begin{tabular}{llll}
\hline $\begin{array}{l}\text { Properties/ } \\
\text { composition }\end{array}$ & $(\%)$ & $\begin{array}{l}\text { Properties/ } \\
\text { composition }\end{array}$ & $(\%)$ \\
\hline Fineness & 89.00 & $\mathrm{CaO}$ & 2.27 \\
$\mathrm{LOI}$ & 1.20 & $\mathrm{~K} 2 \mathrm{O}$ & 1.24 \\
$\mathrm{SiO}_{2}$ & 64.20 & $\mathrm{MgO}$ & 0.69 \\
$\mathrm{Al}_{2} \mathrm{O}_{3}$ & 25.50 & $\mathrm{SO}_{3}$ & 0.20 \\
$\mathrm{Fe}_{2} \mathrm{O}_{3}$ & 3.92 & & \\
\hline
\end{tabular}

\subsection{Mix Compositions}

Three concrete mixes (shown in Table 2) were prepared and tested for slump, vebe time, 7 and 28 day compressive strength and 112 days of drying shrinkage. The recycled aggregate mixes were designed to be equivalent to a well-established $40 \mathrm{MPa}$ control mix. This concrete grade was chosen because Poon et al. (2007) tested a $40 \mathrm{MPa}$ concrete in their experiment program.

The particle size distribution was determined for the aggregates to AS 1141.11.1. While both the control aggregate and the RCA complied with the AS 2758.1 grading requirement for a nominal $20 \mathrm{~mm}$ one-sized aggregate (see Figure 5) it was found that the RCA had significantly more $5 \mathrm{~mm}$ and $10 \mathrm{~mm}$ particles. To avoid differences caused by the variations in grading, less $10 \mathrm{~mm}$ nominal basalt and more RCA was used in the RAC mixes until they had an overall aggregate grading equivalent to the control mix. The same mass of coarse aggregate was used in all mixes as shown in Table 2. Figures 1-2 present the overall aggregate particle size distribution of the control and RAC mixes before and after the aggregate proportion adjustment respectively.

The proportion between the cement, fly ash, pozzolith 370C and fine sand for the fly ash (FARAC) mix with $30 \%$ fly ash partial cement replacement is given in Table 2.

Table 2. Concrete mix proportions

\begin{tabular}{llll}
\hline Material & $\begin{array}{l}\text { Control } \\
\mathrm{kg} / \mathrm{m}^{3}\end{array}$ & $\begin{array}{l}\text { RAC } \\
\mathrm{kg} / \mathrm{m}^{3}\end{array}$ & $\begin{array}{l}\text { FARAC } \\
\mathrm{kg} / \mathrm{m}^{3}\end{array}$ \\
\hline Cement & 350 & 350 & 279 \\
Fly ash & 0 & 0 & 119 \\
RCA & 0 & 940 & 940 \\
20mm crushed basalt & 720 & 0 & 0 \\
10mm crushed basalt & 280 & 60 & 60 \\
Coarse sand & 563 & 563 & 563 \\
Fine sand & 280 & 280 & 200 \\
Water* & 182 & 182 & 179 \\
Pozzolith 370C & $1050 \mathrm{~mL}$ & $1050 \mathrm{~mL}$ & $1194 \mathrm{~mL}$
\end{tabular}

*Initial prediction for water required with SSD aggregates.

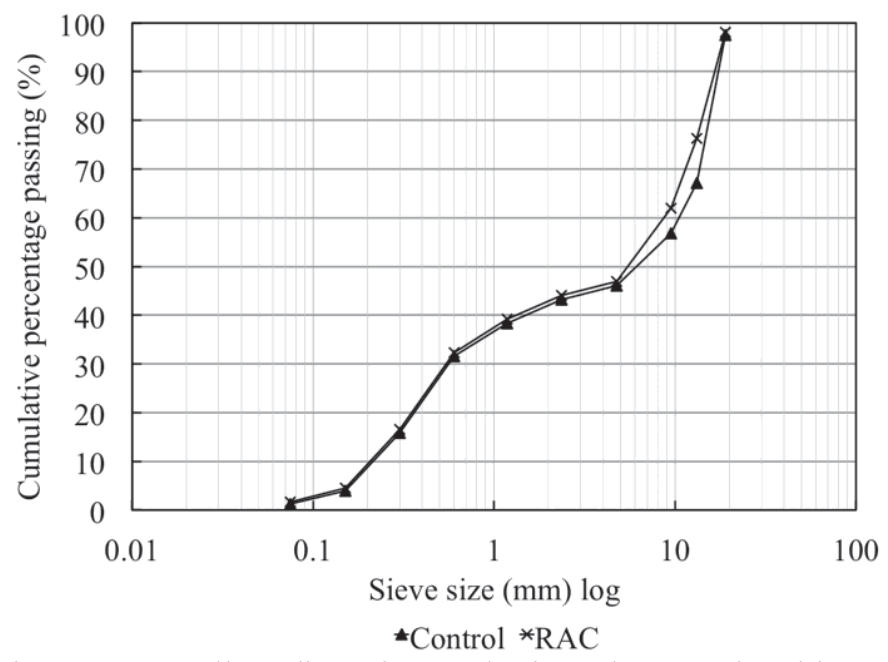

Figure 1. Overall grading of control mix and RAC mix without the aggregate proportion adjustment. 


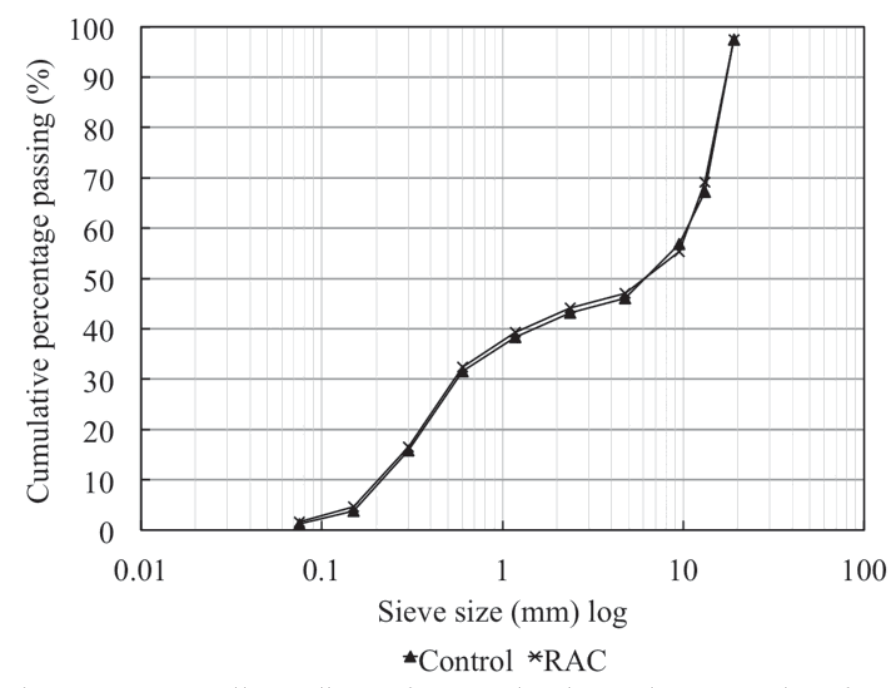

Figure 2. Overall grading of control mix and RAC mix after aggregate proportion adjustment

\subsection{Concrete mixing and fresh concrete testing}

The mixes were prepared for equivalent slumps rather than equivalent water to cement ratios. This approach was adopted because literature reports (Abdelfatah \& Tabsh 2008) that RAC mixes require more water than equivalent mixes incorporating conventional aggregates to achieve and maintain a practical workability. Further, the amount of water in a mix influences the compressive strength and, more importantly in this study, the drying shrinkage of the hardened concrete (Neville 1995).

The concrete mixes were prepared and sampled to AS 1012.1 and AS 1012.2 respectively. Slump tests to AS 1012.3.1 were used to determine the water content required to be added to the mixes. The Vebe tests were undertaken after equivalent slumps were achieved to AS 1012.3.3 in an attempt to provide more information regarding the workability of the mixes.

\subsection{Compressive strength testing}

Three $100 \mathrm{~mm}$ diameter by $200 \mathrm{~mm}$ tall cylinders were prepared to AS 1012.8.1 for each mix for both 7 day and 28 day compressive strength testing. These cylinders were left to dry in their moulds for 24 hours before being de-moulded and placed in lime-saturated water until tested.

The concrete specimens were tested to AS 1012.9 as closely as possible. The cylinders were capped with gypsum plaster on the day, after being removed from the curing tank.

One significant variation from standardised testing in this portion of the study was that the compressive strength cylinders were moist cured in limesaturated water at a temperature of $13^{\circ} \mathrm{C}$ rather than the $23 \pm 2^{\circ} \mathrm{C}$ specified in AS 1012.8.1. This would have notably affected the 7 day compressive strength results.

\subsection{Drying shrinkage testing}

Three concrete drying shrinkage specimens were prepared for each mix as closely to AS 1012.13 as possible. These specimens were left in their moulds for 24 hours before being de-moulded and placed in lime-saturated water in a controlled environment with the water temperature maintained at $23 \pm 2^{\circ} \mathrm{C}$.

After seven days of moist curing the specimens were surface dried and the initial length of the specimens were measured using a vertical comparator five consecutive times until the measurements were within the $0.001 \mathrm{~mm}$ of the mean of the measurements, before being placed on a rack in a controlled environment. Each specimen was measured at $1,2,7,14,21,28,56$ and 112 days after being removed from the moist curing tank. The specimens were measured 3 times at each drying period to check continuously the validity of each measurement and an average was taken for the shrinkage measurement for that specimen at the appropriate drying time. The orientation and placement of each specimen was kept constant throughout the 112 days testing. The specimens were kept in the controlled drying room at all times. The drying environment conditions were maintained to the requirements specified in AS 1012.13.

\section{RESULTS AND DISCUSSIONS}

\subsection{Aggregate property tests}

\subsubsection{Particle shape and texture}

The majority of RCA particles were observed to have similar angular shapes as the crushed basalt control aggregate. The surface texture of the RCA however is somewhat rougher than the basalt aggregate due to mortar adhered to the particles. This rougher surface has the potential to increase the amount of water required for a practical workability. Therefore this property also has the potential to increase the drying shrinkage of the concrete that it is used in.

\subsubsection{Types of rocks in sample}

Through the analysis of thin sections under a microscope the following rock types were found to be present in the RCA product: chert, vain quartz, quartzite (Fig. 3), tertiary basalts (Fig. 4), altered basaltic breccia/sandstone, dacite porphyry, slag and monzanitic porphyry. These are common rock types found in quarries surrounding Sydney, NSW. This analysis was qualitative as it was not possible to determine the relative proportions of each rock type. 


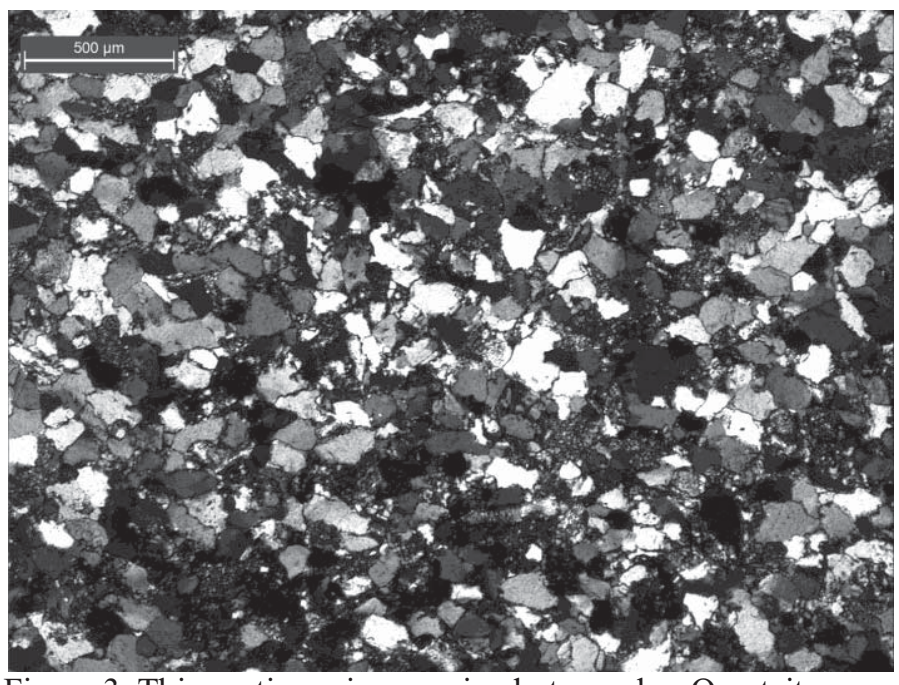

Figure 3. Thin section microscopic photograph - Quartzite

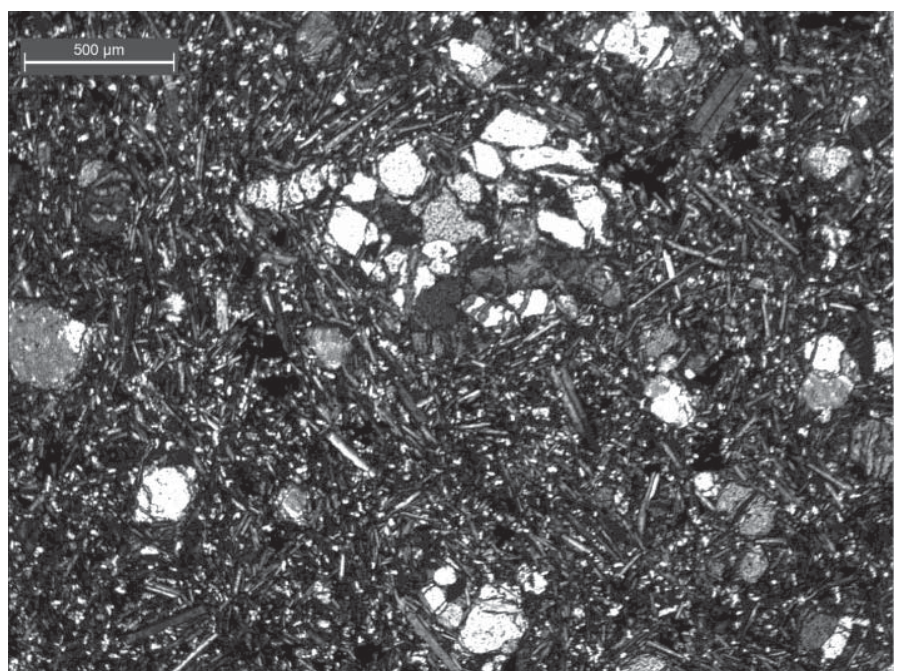

Figure 4. Thin section microscopic photograph - Basalt

\subsubsection{Particle size distribution}

The particle size distribution of the RCA product and the control aggregate was determined following AS 1141.11.1. As shown in Figure 5, both of these aggregates were found to satisfy the grading requirements of a $20 \mathrm{~mm}$ nominal sized aggregate outlined in AS 2758.1.

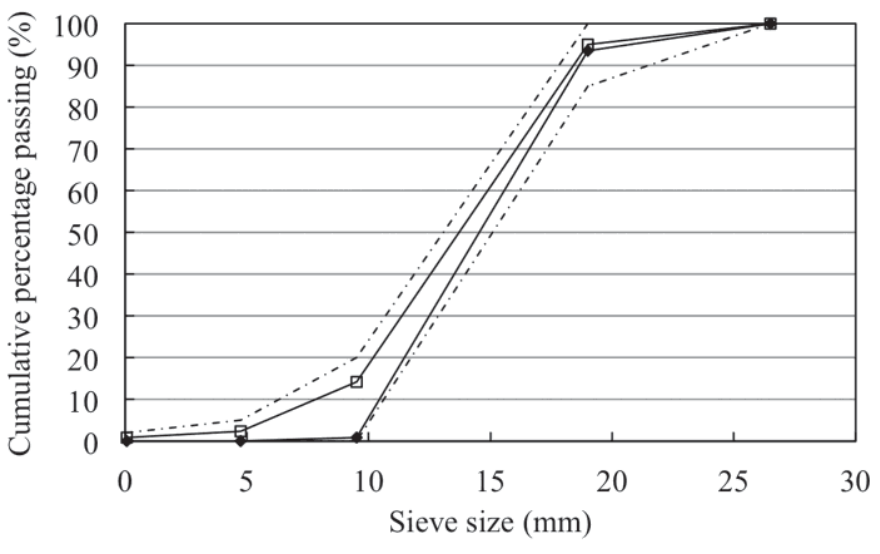

${ }^{*}$ RCA $\bullet 20 \mathrm{~mm}$ Basalt $\cdots$ AS 2758.1 Envelope

Figure 5. Particle size distribution of RCA and control aggregate within the AS $2758.120 \mathrm{~mm}$ nominal size grading requirements.

\subsubsection{Solid contaminants}

Throughout the experiments a range of solid contaminants were observed in the commercial RCA product. These included porcelain, asphalt, wood, masonry and other ceramics. However, the product clearly had a negligible quantity of these contaminants. A sample of $15 \mathrm{~kg}$ was found to only contain $0.4 \%$ solid contaminants by weight (Table 3 ). This very low solid contaminant level has been achieved by strict feedstock separation at the recycling plant where incoming clean concrete waste is both stored and crushed separately from the rest of the incoming material.

Table 3. Aggregate property results

\begin{tabular}{lll}
\hline & $\begin{array}{l}\text { Crushed } \\
\text { Pasalt }\end{array}$ & RCA \\
\hline $\begin{array}{l}\text { Nominal size } \\
\quad \mathrm{mm}\end{array}$ & 20 & 20 \\
$\begin{array}{l}\text { Solid contaminants } \\
\quad \%\end{array}$ & 0.0 & 0.4 \\
$\begin{array}{l}\text { Water absorption } \\
\quad \%(A S ~ 1141.6 .2)\end{array}$ & 1.92 & 4.69 \\
$\begin{array}{l}\text { Apparent particle density } \\
\mathrm{kg} / \mathrm{m}^{3} \text { (AS 1141.6.2) }\end{array}$ & 2799 & 2739 \\
$\begin{array}{l}\text { Dry basis particle density } \\
\mathrm{kg} / \mathrm{m}^{3} \text { (AS 1141.6.2) }\end{array}$ & 2656 & 2359 \\
$\begin{array}{l}\mathrm{SSD} \text { basis particle density } \\
\mathrm{kg} / \mathrm{m}^{3} \text { (AS 1141.6.2) }\end{array}$ & 2707 & 2498 \\
\hline
\end{tabular}

\subsubsection{Water Absorption}

The water absorption of the RCA and the $20 \mathrm{~mm}$ control aggregate were determined to AS 1141.6.2. Two samples were tested for both aggregates and the results averaged. As shown in Table 3, the RCA was found to have a significantly greater water absorption than the natural crushed basalt aggregate. This is due to the porous nature of the mortar adhered to the particles of the RCA. To overcome concrete workability issues it is therefore important to maintain the RCA in the saturated surface dry condition before mixing. If a mix was prepared with the aggregates below the saturated surface dry condition, the mix would require more water to maintain a practical degree of workability. This in return could increase the drying shrinkage while decreasing the compressive strength of the concrete.

\subsubsection{Particle densities}

The apparent, dry basis and SSD basis particle densities were determined using the pycnometer method (AS 1141.6.2). Two samples were tested for both the RCA and the $20 \mathrm{~mm}$ control aggregate and the results were averaged. The RCA can be considered to be a normal weight concrete aggregate based on the definition in AS 2758.1.

Table 3 illustrates that the RCA has a significantly lower SSD basis and dry basis particle densities than the control aggregate. As these densities 
consider both the impermeable and permeable voids the results show that the RCA particles are more porous and less dense when considering the complete volume of a particle.

It is likely that the higher porosity/ lower density means that the RCA particles are less rigid and have lower elastic moduli than conventional aggregates due to the presence of adhered mortar. The elastic properties of coarse aggregates have a great effect on the drying shrinkage of concrete. While concrete dries and the adsorbed water is lost from the hydrated cement, tensile strains are induced in the cement, causing the aggregates to go into compression. The higher the elastic modulus or rigidity of the aggregates, the greater the restraint against these shrinkage strains can be provided thus decreasing the drying shrinkage of the concrete (Neville 1995). Therefore low elastic properties found in RCA could provide one reason for the high drying shrinkages found in RAC.

\subsection{Fresh concrete properties}

The final slump test and vebe test results for each mix are shown in Table 4. It can be seen that while all the slumps are similar, the FARAC required significantly less vebe time, although it is of the same order of magnitude.

Table 4. Consistency testing results

\begin{tabular}{llll}
\hline Consistency test & Control & RAC & FARAC \\
\hline $\begin{array}{c}\text { Slump } \\
\text { mm (AS 1012.3.1) }\end{array}$ & 80 & 77 & 88 \\
$\begin{array}{c}\text { Vebe } \\
\text { sec (AS 1012.3.3) }\end{array}$ & 1.6 & 1.47 & 0.78 \\
\hline
\end{tabular}

\subsection{Compressive strength}

The 7 day compressive strength tests indicated that the mixes were adequate and the experiment could continue. All of the control mix specimens achieved compressive strengths greater than $40 \mathrm{MPa}$ at 28 days of curing as shown in Figure 5, indicating that the mix was successful in achieving a $40 \mathrm{MPa}$ grade mix. Figure 6 shows that the RAC mix was unsuccessful in achieving a $40 \mathrm{MPa}$ concrete mix. This could be due to the following reasons:

a) Higher water content for slump due to rougher aggregate surface textures and some possible action from the higher water absorption as it is hard to maintain/provide SSD condition.

b) Lower strength and density of RCA particles due to adhered mortar on surfaces.

c) Lower overall strength of RCA rock particles.

The FARAC mix achieved significantly lower compressive strength results than the control due to the pozzolanic nature of fly ash. This mix would gain strength at a slower rate.

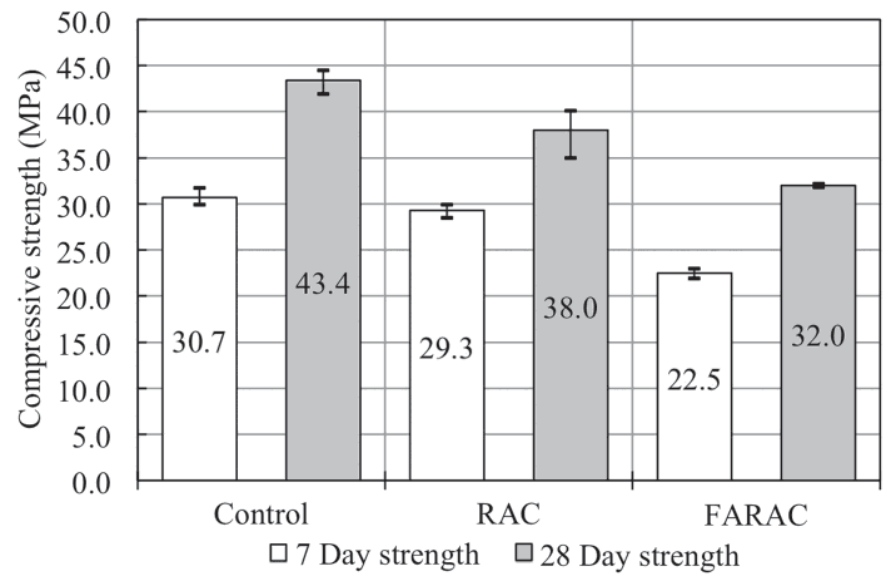

Figure 6. Average compressive strength results with max and min results.

\subsection{Drying shrinkage}

As shown in Figure 6, the RAC mix was measured to have a significantly greater drying shrinkage than the control mix throughout the experiment with a $25 \%$ average increase in the 112 day drying shrinkage to the control. The FARAC mix only had a $7 \%$ average increase in the 112 day drying shrinkage to the control mix. This result supports the finding by Poon et al. (2007) that fly ash as a partial cement replacement can reduce the 112 day drying shrinkage of RAC.

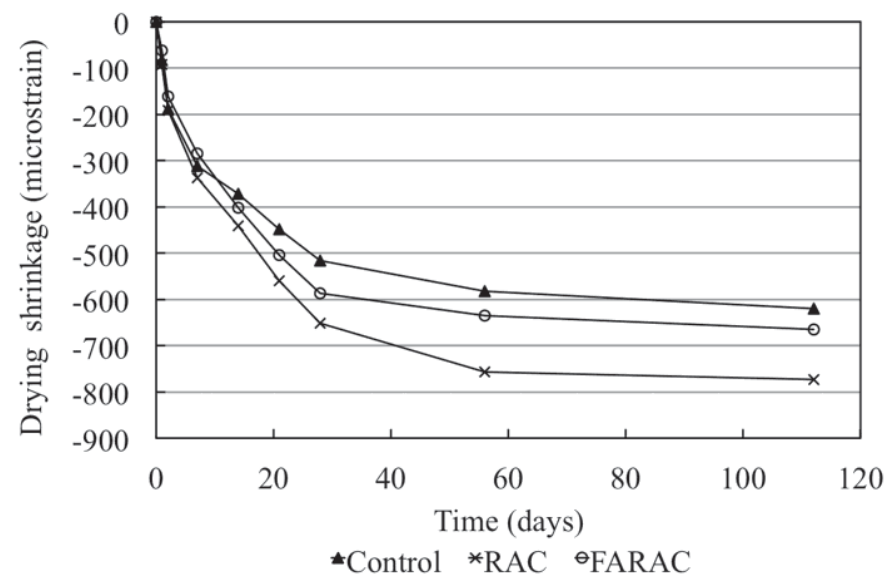

Figure 7. Average drying shrinkage results.

\section{SUMMARY AND CONCLUSIONS}

The following was found/concluded from this study:

- The RCA was a high quality product with negligible solid contaminants. This was achieved by effective recycling procedures where incoming clean concrete feedstock is identified at the gate then stored and crushed separately from the rest of the feedstock materials.

- Despite being a quality product, the RCA had inferior aggregate properties compared to the control aggregate and the majority of conventional concrete aggregates. This is primarily due to the presence of adhered mortar on the aggregate par- 
ticles. This mortar produces rougher particle surface textures, higher water absorptions, higher porosity and lower particle densities.

- The analysis of thin sections indicated the sheer variability of materials that can be found in one sample of a RCA product produced in Western Sydney.

- The compressive strength testing indicated that RAC suffered decreased compressive strengths compared to an equivalent mix incorporating conventional aggregates. For this reason, lower percentages of RCA to conventional aggregates would be valid.

- The 7 day compressive strength results would have been affected by the low moist curing temperature applied to the specimens.

- RAC has significantly greater values of drying shrinkage compared to an equivalent mix incorporating conventional aggregates. When effectively utilising $100 \% \mathrm{RCA}$ as a coarse aggregate in a ' $40 \mathrm{MPa}$ ' concrete this increase can be to the extent of $25 \%$ at 112 days of drying.

- The increase in drying shrinkage could be due to lower elastic modulus of the adhered mortar on the RCA particles; the rougher texture of the mortar affecting the amount of water required in a workable concrete; the varying types of rocks in the RCA; and the high water absorption of the RCA particles requiring more water when the aggregates are not perfectly in the SSD condition.

- The FARAC mix drying shrinkage results support the results of Poon et al. (2007) where the drying shrinkage of RAC was reduced by the addition of fly ash as a $30 \%$ partial cement replacement. The addition of fly ash to reduce the drying shrinkage of RAC may be applicable for low concrete strength grade applications such as pavements.

- For RAC applications requiring higher compressive strength grades, concrete consisting of lower levels of RCA substitution for conventional aggregates would likely be more practical.

Improvements are still required in the performance of structural concretes that incorporate recycled aggregates. This work indicates that using 100\% recycled coarse aggregates results in a small loss of strength when compared to a virgin basalt aggregate. More tests are needed to compare with other rock types. The presence of a range of rocks within the RCA will result in concretes being similar to those made with the weakest aggregates.

\section{ACKNOWLEDGEMENTS}

The authors are grateful to Mr Jose Abrantes and A./Prof Christopher Fergusson of the School of Earth and Environmental Sciences at the University of Wollongong for assistance in preparing the thin sections and analysis of rock types. Thanks are also due to Mr Fernando Escribano and Mr Ian Laird for technical assistance throughout the project.

\section{REFERENCES}

Abdelfatah, A.S. \& Tabsh, S.W. 2008. Influence of recycled concrete aggregates on strength properties of concrete. Construction and Building Materials 23(2): 1163-1167.

Australian Bureau of Statistics. 2007. Waste generation, Australia's Environment: Issues and Trends 2007, 4613.0.

Australian Standard AS 1012.1. Methods of testing concrete, Method 1: Sampling of fresh concrete, Standards Australia, 1993.

Australian Standard AS 1012.2. Methods of testing concrete, Method 2: Preparation of concrete mixes in the laboratory, Standards Australia, 1994.

Australian Standard AS 1012.3.1. Methods of testing concrete, Method 3.1: Determination of properties related to the consistency of concrete - Slump test, Standards Australia, 1998.

Australian Standard AS 1012.3.3. Methods of testing concrete, Method 3.3: Determination of properties related to the consistency of concrete - Vebe test, Standards Australia, 1998.

Australian Standard AS 1012.8.1. Methods of testing concrete, Method of making and curing concrete, Compression and indirect tensile test specimens, Standards Australia, 2000.

Australian Standard AS 1012.9. Methods of testing concrete, Method 9: Determination of the compressive strength of concrete specimens, Standards Australia, 1999.

Australian Standard AS 1012.13. Methods of testing concrete, Method 13: Determination of the drying shrinkage of concrete for samples prepared in the field or in the laboratory, Standards Australia, 1992.

Australian Standard AS 1141.6.2. Methods for sampling and testing aggregates, Method 6.1: Particle density and water absorption of coarse aggregate - Pycnometer method, Standards Australia, 1996.

Australian Standard AS 1141.11.1. Methods for sampling and testing aggregates, Method 11.1: Particle size distribution Sieving method, Standards Australia, 2009.

Australian Standard AS 2758.1. Aggregate and rock for engineering purposes, Part 1: Concrete aggregates, Standards Australia, 1998.

Corinaldesi, V. \& Moriconi, G. 2009. Influence of mineral additions on the performance of $100 \%$ recycled aggregate concrete. Construction and Building Materials 23(8): 28692876.

CSIRO. 2002. Guide to the use of recycled concrete and masonry materials. Standards Australia, HB 155-2002.

Montgomery, D. \& Sturgiss, D. 1996. Properties of concrete incorporating recycled concrete aggregates. Institution of Engineers: 153.

Neville, A. M. (ed. 4) 1995. Properties of concrete. London: Pearson.

Pickin, J. 2009. Australian landfill capacities into the future, Department of the Environment, Water, Heritage and the Arts, Australian Government.

Poon, C., Kou, S. \& Chan, D. 2007. Influence of fly ash as cement replacement on the properties of recycled aggregate concrete. Journal of Materials in Civil Engineering 19(2): 709-717.

Sagoe-Crentsil, K., Brown, T. \& Taylor, A.H. 2001. Performance of concrete made with commercially produced coarse recycled concrete aggregate. Cement and Concrete Research 31(5): 707-712. 